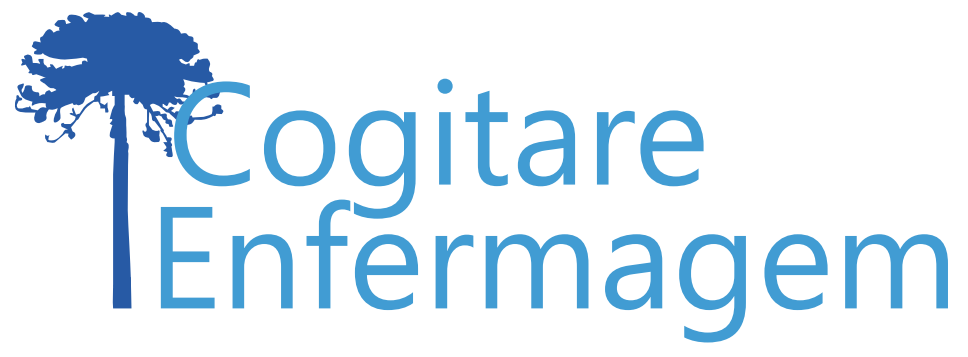

\title{
CONSTRUÇÃO E VALIDAÇÃO DE QUESTIONÁRIO PARA AVALIAÇÃO DE CONHECIMENTO SOBRE RESSUSCITAÇÃO CARDIOPULMONAR*
}

\author{
Mateus Goulart Alves ${ }^{1}$, Vanessa Oliveira Silva Pereira², Denise Ferreira Gomide Batista ${ }^{3}$, \\ Aldenora Laísa Paiva de Carvalho Cordeiro ${ }^{4}$, Juliana da Silva Garcia Nascimento ${ }^{5}$, Maria Célia \\ Barcellos Dalri6
}

\section{RESUMO}

Objetivo: construir e validar um questionário sobre Ressuscitação Cardiopulmonar no adulto em Suporte Básico de Vida, com o uso do Desfibrilador Externo Automático, no ambiente hospitalar. Metodologia: pesquisa aplicada, realizada na Escola de Enfermagem de Ribeirão Preto da Universidade de São Paulo, no período de janeiro de 2017 a março de 2018. Composta por 16 experts em Urgência e Emergência, para selecioná-los foi adotado os critérios de Fehring. Foram aplicadas as regras do manual do Conselho Nacional de Examinadores Médicos e diretrizes da American Heart Association. Utilizou-se estatística descritiva e análise de concordância interavaliadores por AC1 de Gwet. Validado em relação à organização, objetividade e clareza.

Resultados: questionário validado com 20 questões de Múltipla Escolha com concordância interavaliadores "quase perfeita".

Conclusão: o questionário mostrou-se válido para utilização como instrumento de avaliação sobre o assunto abordado.

DESCRITORES: Inquéritos e Questionários; Ensino; Aprendizagem; Avaliação Educacional; Reanimação Cardiopulmonar.

\footnotetext{
*Artigo extraído da dissertação de mestrado "Objetos contemporâneos para ensino-aprendizagem da ressuscitação cardiopulmonar". Universidade de São Paulo, 2018.
}

COMO REFERENCIAR ESTE ARTIGO:

Alves MG, Pereira VOS, Batista DFG, Cordeiro ALP de C, Nascimento J da SG, Dalri MCB. Construção e validação de um questionário para avaliação de conhecimento sobre ressuscitação cardiopulmonar. Cogitare enferm. [Internet]. 2019 [acesso em "colocar data de acesso, dia, mês abreviado e ano"]; 24. Disponível em: http://dx.doi.org/10.5380/ce.v24i0.64560.

Este obra está licenciado com uma Licença Creative Commons Atribuição 4.0 Internacional.

${ }^{1}$ Enfermeiro. Mestre em Enfermagem. Docente da Faculdade Atenas. Passos, MG, Brasil.

${ }^{2}$ Enfermeira. Mestre em Enfermagem. Docente na Universidade do Estado de Minas Gerais. Passos, MG, Brasil. $\odot$

${ }^{3}$ Enfermeira. Mestranda em Enfermagem. Universidade de São Paulo. Ribeirão Preto, SP, Brasil. $(0$

${ }^{4}$ Enfermeira. Doutoranda em Enfermagem. Universidade de São Paulo. Ribeirão Preto, SP, Brasil.

${ }^{5}$ Enfermeira. Doutoranda em Enfermagem. Universidade de São Paulo. Ribeirão Preto, SP, Brasil.?

${ }^{6}$ Enfermeira. Doutora em Enfermagem. Docente de Enfermagem da Universidade de São Paulo. Ribeirão Preto, SP, Brasil. 


\title{
CONSTRUCTION AND VALIDATION OF A QUESTIONNAIRE FOR CARDIOPULMONARY RESUSCITATION KNOWLEDGE ASSESSMENT
}

\author{
ABSTRACT \\ Objective: To construct and validate a questionnaire related to adult cardiopulmonary \\ resuscitation in Basic Life Support, using the Automatic External Defibrillator, in the hospital \\ environment. \\ Methodology: applied study, conducted at the University of São Paulo at Ribeirão Preto \\ College of Nursing, from January 2017 to March 2018. Participants were 16 Urgency and \\ Emergency experts, with Fehring's criteria used to select them. The rules of the National \\ Council of Medical Examiners manual and guidelines of the American Heart Association were \\ applied. Descriptive statistics and inter-rater agreement analysis through Gwet's AC1 were \\ used. The questionnaire was validated in relation to organization, objectivity and clarity. \\ Results: a validated questionnaire with 20 multiple choice questions with "almost perfect" \\ inter-rater agreement was produced. \\ Conclusion: the questionnaire was shown to be valid for use as an assessment instrument on \\ the subject addressed.
}

DESCRIPTORS: Surveys and Questionnaires; Teaching; Learning; Educational Assessment; Cardiopulmonary resuscitation.

\section{CONSTRUCCCIÓN Y VALIDACIÓN DE CUESTIONARIO PARA AVALIACION DE CONOCIMIENTO SOBRE REANIMACIÓN CARDIOPULMONAR}

\begin{abstract}
RESUMEN:
Objetivo: construir y validar un cuestionario sobre Reanimación de adulto, en Soporte Básico de Vida, con el uso de Desfibrilador Externo Automático, en ambiente hospitalario.

Metodología: investigación aplicada, realizada en la Escuela de Enfermería de Ribeirao Preto de la Universidad de Sao Paulo, en el período de enero de 2017 a marzo de 2018. Estuvo compuesta por 16 especialistas en Urgencia y Emergencia; para seleccionarlos fueron adoptados los criterios de Fehring. Se aplicaron las reglas del manual del Consejo Nacional de Examinadores Médicos y las directrices de la American Heart Association. Se utilizó la estadística descriptiva y el análisis de concordancia entre evaluadores AC1 de Gwet. El cuestionario fue validado en relación a la organización, objetividad y clareza.

Resultados: el cuestionario fue validado con 20 preguntas de Múltiple Elección con concordancia entre evaluadores "casi perfecta".

Conclusión: el cuestionario se mostró válido para utilización como instrumento de evaluación sobre el asunto abordado.
\end{abstract}

DESCRIPTORES: Encuestas y Cuestionarios; Enseñanza; Aprendizaje; Evaluación educativa; Reanimación cardiopulmonar. 
A educação em Ciências da Saúde exige sistemas de avaliação precisos, eficientes e diversificados, capazes de identificar o conhecimento adquirido no processo de ensino, em alto nível de competência e segurança $a^{(1-2)}$. É indispensável avaliar a aprendizagem por meio de instrumentos válidos e confiáveis ${ }^{(3)}$ e salienta-se que é necessária a criação de instrumentos que contribuam para ações e intervenções qualificadas na área de saúde ${ }^{(4)}$.

Os efeitos no processo de ensino-aprendizagem surgem quando a própria avaliação exige a aprendizagem, impondo que as avaliações sejam implementadas com o objetivo de agregar valor pedagógico(5), e não só o caráter formativo e/ou somativo. Os métodos de avaliação devem inspirar a necessidade de aprendizagem ${ }^{(1)}$ e refletir na aquisição de conhecimento e habilidades, permitindo que os estudantes percebam que há efeito de aprendizado e não somente efeito avaliativo ou método de punição(b).

O resultado alcançado em questionários estruturados com a Questão de Múltipla Escolha (QME), adequadamente elaborados, correlacionam-se significativamente com as habilidades e o pensamento crítico, confirmando que podem avaliar níveis mais altos de habilidades cognitivas ${ }^{(7)}$ e não somente um levantamento do conhecimento ${ }^{(8)}$. Espera-se que o estudante, ao responder questionários estruturados com $\mathrm{QME}$, tenha reafirmada a amplitude da aprendizagem ${ }^{(9)}$.

A QME é geralmente aceita como forma eficiente, objetiva e confiável para avaliação das habilidades e domínio cognitivo(10). Suscita processos cognitivos para o raciocínio clínico (11), desde que elaboradas sem armadilhas, com distratores adequados, pois falhas na qualidade da QME ameaçam a validade da avaliação(12).

Em Ressuscitação Cardiopulmonar (RCP), a utilização de QME adequadamente elaboradas evidencia benefícios no processo de ensino-aprendizagem, pela confiabilidade aceitável e dificuldade aproximadamente igual em todas as questões ${ }^{(13)}$.

Apesar dos avanços na ciência em relação à RCP, o Suporte Básico de Vida (SBV) continua sendo um fator crítico na determinação de resultados no atendimento à Parada Cardiorrespiratória (PCR), sendo necessário incorporar as evidências científicas publicadas recentemente para ensino-aprendizagem da RCP em SBV ${ }^{(14)}$.

Há profissionais de saúde que apresentam alto nível de ansiedade e medo em estar envolvido em cenários de RCP pela falta de conhecimento, afetando diretamente as taxas de sobrevivência e qualidade pós-reanimação(12), assim, torna-se necessário o desenvolvimento de intervenções capazes de promover oportunidades de melhoria para o atendimento da PCR, com ênfase em recomendações internacionais atualizadas ${ }^{(11)}$.

Nessa perspectiva, emerge a necessidade em desenvolver e validar um questionário para avaliação de conhecimento sobre RCP no adulto em SBV com o uso do Desfibrilador Externo Automático (DEA) no ambiente hospitalar, para avaliação de estudantes e profissionais de saúde. Com a implementação de métodos avaliativos por meio de questionários, estruturados adequadamente seguindo critérios metodológicos adequados, é possível afirmar que tais instrumentos corroboram para prática de avaliação e fomentam aprendizagem desejável, com alcance de projeção do conhecimento e raciocínio clínico.

O uso de questionários com QME refinados e nivelados em dificuldade apropriada e com número adequado de itens permitem melhor identificação da efetividade da avaliação(15). A OME de alta qualidade requer experiência e conhecimento sobre a adequada metodologia de elaboração( ${ }^{(1,16)}$, pois o objetivo é o preparo de questões sem distratores para a obtenção de resultados que reflitam com precisão o nível de conhecimento(17).

A QME considerada adequadamente construída consiste em um enunciado/ pergunta, podendo ser um caso clínico, seguido de quatro opções de escolha, uma correta e três incorretas ${ }^{(18)}$. É recomendado o uso de quatro alternativas, com questões de 
alta qualidade ${ }^{(16)}$. Nesse questionário foi adotado QME com quatro opções de resposta pela atual e permanente credibilidade em aplicação de avaliações com quatro opções de resposta.

A disponibilização de questionários confiáveis é de grande valia para a comunidade acadêmica, visto que possibilitará sua aplicação nos processos de avaliação de maneira clara, objetiva e organizada. Essencial para atendimento das exigências da contemporaneidade e certamente possibilitará o aperfeiçoamento do processo de ensino-aprendizagem, e esse fato poderá impactar na qualidáde e resultado da assistência prestada ao paciente em PCR.

Portanto, este estudo teve como objetivo desenvolver e validar um questionário elaborado com $\mathrm{QME}$, para avaliação teórica sobre RCP no adulto em SBV com o uso do DEA no ambiente hospitalar.

\section{MÉTODO}

Trata-se de uma pesquisa aplicada(18) que envolve o desenvolvimento e validação de questionário com $20 \mathrm{QME}$ embasado nas diretrizes da American Heart Association $(\mathrm{AHA})^{(19)}$ e nas orientações do National Board of Medical Examiners (NBME) ${ }^{(20)}$, abordando conhecimento sobre RCP no adulto em SBV com o uso do DEA no ambiente hospitalar.

Desenvolvido em duas etapas: construção do questionário e validação do conteúdo com experts, no período de janeiro de 2017 a março de 2018 em uma universidade pública no Sudeste do Brasil.

A validação foi realizada com 16 experts da área de Urgência e Emergência (UE) selecionados intencionalmente ${ }^{(18)}$. Para seleção, foram utilizados os critérios de Fehring ${ }^{(21)}$ que orientam um cálculo de score, considerando: quatro pontos para titulação de Mestre em Enfermagem; um ponto para titulação de Mestre em Enfermagem com dissertação na área de interesse do estudo; dois pontos para tese de doutorado na área do estudo; um ponto para prática clínica de pelo menos um ano na área de interesse; dois pontos para certificado de prática clínica (especialização) na área de interesse; dois pontos para publicação de pesquisa relevante para a área de interesse e dois pontos para publicação de artigo sobre o tema em periódico de referência.

Para selecioná-los, foi realizado levantamento nos grupos de pesquisa relacionados às áreas de UE, busca por autores de estudos relacionados à PCR/RCP e docentes da área de UE em Instituição de Ensino Superior (IES) de regiões diversas. Foi adotado como critérios de inclusão: pontuação mínima de cinco pontos e atuação/formação/docência na área de UE.

Foi enviado convite, via e-mail, para 26 experts, 18 responderam com aceite em participar e 16 finalizaram o processo de validação. Aos que aceitaram, foi enviado via correio eletrônico ou impresso, de acordo com a preferência do expert, os seguintes itens: Termo de Consentimento Livre e Esclarecido (TCLE), Orientações gerais relacionadas ao processo de validação e Guia para validação do questionário, contendo as $\mathrm{QME}$, roteiro explicativo e instrumento para validação.

Foi solicitado que a avaliação fosse realizada em, no máximo, 30 dias e, que após a avalição, o TCLE e os instrumentos de avaliação deveriam ser enviados ao pesquisador devidamente assinados e preenchidos. O guia explicativo para a validação foi estruturado para otimizar o processo de validação pelos experts, nele foi exposto os aspectos a serem considerados no processo de validação.

Para validação, foi adaptado o instrumento desenvolvido por Bellan ${ }^{(22)}$, avaliando os aspectos relacionados à organização, clareza, objetividade, com opções de resposta 
dicotômicas (Sim/Não) em cada item avaliado. Aos experts foi solicitado para considerar os itens destacados pelo $\mathrm{NBME}^{(20)}$ e as diretrizes da $\mathrm{AHA}^{(19)}$.

O instrumento para a validação foi estruturado em um quadro, apresentando, sequencialmente, em cada coluna: enunciado, alternativas da questão e itens a serem avaliados (organização, objetividade e clareza). Foi solicitado aos experts, na identificação de ausência de informações necessárias e/ou informações desnecessárias, e em discordẩncias, para que registrassem sugestões e comentários, em área específica do instrumento.

Para a organização dos dados foram confeccionadas planilhas no programa Microsoft Excel 2010®, com dupla digitação, com posterior validação para obtenção de dados fidedignos. O programa utilizado para as análises de concordância foi o Programa R versão 3.4.1. Em todas as análises foi adotado o nível de significância de $5 \%(p>0.05)$

A análise de dados referente à caracterização dos experts foi realizada por meio de estatística descritiva, frequência, percentagem e média. Para avaliar a concordância interavaliadores entre os 16 juízes, foi utilizada a estatística $A C 1$ desenvolvida por Gwet ${ }^{(23)}$.

Para categorização da concordância inter-avaliador, através da estatística AC1, foram considerados os valores definidos por Landis e Kock(24), sendo <0,00: Pobre concordância, 0,00 - 0,20: Leve concordância; 0,21 - 0,40: Aceitável concordância; 0,410,60: Moderada concordância; 0,61 - 0,80: Considerável Concordância; 0,81 - 1,00: Quase perfeita concordância. A concordância foi considerada satisfatória para índices com valores superiores a 0,60 , pois assim oferecem benchmarks úteis para a discussão de resultados ${ }^{(24)}$.

A pesquisa foi aprovada por Comitê de Ética em Pesquisa, sob o parecer número 2.002.839 de acordo com a legislação vigente. Bellan ${ }^{(22)}$ concedeu a autorização para utilização e adaptação do instrumento.

\section{RESULTADOS}

Na validação do questionário, os experts eram 16 (100\%) enfermeiros; 13 (81,25\%) constituíram-se por mulheres; idade variou entre 29 e 55 anos $( \pm 7,33)$; tempo de formação entre quatro e 32 anos $( \pm 7,51) ; 15(93,75 \%)$ possuem mestrado, $10(62,50 \%)$ doutorado e três $(18,75 \%)$ pós-doutorado; oito $(50 \%)$ atuam em docência no ensino superior; 15 $(93,75 \%)$ possuem prática clínica de pelo menos um ano em UE no adulto; 13 (81,25\%) participaram de eventos relacionados à área UE nos últimos dois anos; distribuição geográfica abrangente (regiões Sudeste, Centro-Oeste e Nordeste do Brasil), atuantes em IES e instituições de saúde públicas e privadas. Em relação à classificação pelos critérios de Fehring(21), a maioria dos experts com pontuação maior ou igual a $10(62,5 \%)$ e quatro (25\%) com pontuação máxima, 14 pontos.

A Tabela 1 apresenta as respostas dos experts, relacionada à validação das QME.

Tabela 1 - Avaliação dos experts, relacionada à validação do questionário em relação à organização, objetividade e clareza. Ribeirão Preto, SP, Brasil, 2018 (continua)

\begin{tabular}{|c|c|c|c|c|c|c|c|c|c|c|c|c|}
\hline \multirow[t]{3}{*}{ Questão } & \multicolumn{4}{|c|}{ Organização } & \multicolumn{4}{|c|}{ Objetividade } & \multicolumn{4}{|c|}{ Clareza } \\
\hline & \multicolumn{2}{|c|}{ Sim } & \multicolumn{2}{|c|}{ Não } & \multicolumn{2}{|c|}{ Sim } & \multicolumn{2}{|c|}{ Não } & \multicolumn{2}{|c|}{ Sim } & \multicolumn{2}{|c|}{ Não } \\
\hline & $\mathbf{n}$ & $\%$ & $\mathbf{n}$ & $\%$ & $\mathbf{n}$ & $\%$ & $\mathbf{n}$ & $\%$ & $\mathbf{N}$ & $\%$ & $\mathbf{n}$ & $\%$ \\
\hline 1 & 15 & 93,75 & 1 & 6,25 & 13 & 81,25 & 3 & 18,75 & 11 & 68,75 & 5 & 31,25 \\
\hline 2 & 14 & 87,5 & 2 & 12,5 & 11 & 68,75 & 5 & 31,25 & 10 & 62,5 & 6 & 37,5 \\
\hline
\end{tabular}




\begin{tabular}{|c|c|c|c|c|c|c|c|c|c|c|c|c|}
\hline 3 & 16 & 100 & & & 15 & 93,25 & 1 & 6,25 & 15 & 93,25 & 1 & 6,25 \\
\hline 4 & 15 & 93,75 & 1 & 6,25 & 16 & 100 & & & 14 & 87,5 & 2 & 12,5 \\
\hline 5 & 16 & 100 & & & 15 & 93,25 & 1 & 6,25 & 13 & 81,25 & 3 & 18,75 \\
\hline 6 & 15 & 93,75 & 1 & 6,25 & 14 & 87,5 & 2 & 12,5 & 14 & 87,5 & 2 & 12,5 \\
\hline 7 & 16 & 100 & & & 16 & 100 & & & 15 & 93,75 & 1 & 6,25 \\
\hline 8 & 16 & 100 & & & 16 & 100 & & & 16 & 100 & & \\
\hline 9 & 16 & 100 & & & 15 & 93,75 & 1 & 6,25 & 14 & 87,5 & 2 & 12,5 \\
\hline 10 & 15 & 93,75 & 1 & 6,25 & 15 & 93,75 & 1 & 6,25 & 14 & 87,5 & 2 & 12,5 \\
\hline 11 & 16 & 100 & & & 15 & 93,75 & 1 & 6,25 & 15 & 93,25 & 1 & 6,25 \\
\hline 12 & 15 & 93,75 & 1 & 6,25 & 15 & 93,75 & 1 & 6,25 & 15 & 93,75 & 1 & 6,25 \\
\hline 13 & 15 & 93,25 & 1 & 6,25 & 15 & 93,75 & 1 & 6,25 & 14 & 87,5 & 2 & 12,5 \\
\hline 14 & 15 & 93,25 & 1 & 6,25 & 13 & 81,25 & 3 & 18,75 & 14 & 87,5 & 2 & 12,5 \\
\hline 15 & 15 & 93,75 & 1 & 6,25 & 14 & 87,5 & 2 & 12,5 & 14 & 87,5 & 2 & 12,5 \\
\hline 16 & 16 & 100 & & & 12 & 75 & 4 & 25 & 14 & 87,5 & 2 & 12,5 \\
\hline 17 & 16 & 100 & & & 16 & 100 & & & 15 & 93,75 & 1 & 6,25 \\
\hline 18 & 16 & 100 & & & 15 & 93,75 & 1 & 6,25 & 15 & 93,75 & 1 & 6,25 \\
\hline 19 & 16 & 100 & & & 15 & 93,75 & 1 & 6,25 & 16 & 100 & & \\
\hline 20 & 16 & 100 & & & 15 & 93,75 & 1 & 6,25 & 16 & 100 & & \\
\hline Total & 310 & 96,89 & 10 & 3,11 & 291 & 90,94 & 29 & 9,06 & 284 & 88,75 & 36 & 11,25 \\
\hline
\end{tabular}

Ao considerar a avaliação de organização, objetividade e clareza, as OME foram avaliadas positivamente, sendo organização 310/320 (96,89\%), objetividade 291/320 $(90,94 \%)$ e clareza $284 / 320(88,75 \%)$ com respostas positivas (sim).

Ao verificar a concordância inter-avaliadores nas $\mathrm{QME}$, evidenciou-se "concordância quase perfeita" nos itens relacionados à organização e objetividade, com $A C 1=0,93$ e $A C 1=0,81(p<0,0001)$. Ao se tratar dos itens relacionados à clareza alcançou-se "concordância considerável" entre os avaliadores com $A C 1=0,76(p<0,0001)$, conforme apresentado na Tabela 2.

Tabela 2 - Concordância inter-avaliadores, relacionada à validação da QME em relação à organização, objetividade e clareza. Ribeirão Preto, SP, Brasil, 2018

\begin{tabular}{llcl} 
Variável & AC1 & EP_AC1 & p-valor* \\
\hline Organização & 0,93 & 0,019 & $<0,0001$ \\
\hline Objetividade & 0,81 & 0,042 & $<0,0001$ \\
\hline Clareza & 0,76 & 0,047 & $<0,0001$
\end{tabular}

*Nível de significância de $5 \%(p<0.05)$ 
As sugestões, comentários e apontamentos realizados pelos experts foram avaliados e os que estavam em consonância com as diretrizes da $\mathrm{AH} \mathrm{A}^{(19)}$ foram alterados. Destacase que a maioria das recomendações foram em relação à alteração de termos/palavras, reorganização do texto (alternativa e enunciado) e inclusão de informações nas alternativas e/ou enunciado.

O questionário (ANEXO A) elaborado neste estudo foi construído por $20 \mathrm{QME}$ com quatro alternativas cada $(A-B-C-D)$, sendo três incorretas e uma delas correta (ANEXO B), denominado "Conhecimento sobre RCP em adultos no SBV com uso do DEA no ambiente hospitalar", tendo como público população-alvo estudantes e profissionais de saúde.

\section{DISCUSSÃO}

O desenvolvimento e validação deste questionário foi estruturado para atender à necessidade atual de aplicação de estratégias contemporâneas de avaliação, disseminando nova possibilidade de avaliação sobre o RCP no adulto em SBV com uso do DEA no ambiente hospitalar.

Vários estudos mostram a necessidade de validação por experts dos instrumentos de avaliação, garantindo a qualidade necessária para a aplicação e tornando-se ferramenta adequada no processo de ensino-aprendizagem ${ }^{(2,7-9,77,17,25)}$. O questionário elaborado neste estudo foi validado em relação à organização, objetividade e clareza, avaliadas positivamente pelos experts.

Recomenda-se consistentemente que os especialistas possuam experiência na área do objeto que está sendo avaliado(26). Identificou-se o perfil dos experts possuía titulação de doutorado, experiência em docência e prática clínica em UE, distribuídos nas regiõ̃es Norte, Sudeste e Centro-oeste do Brasil, o que garantiu credibilidade no processo de validação.

São necessárias explicações claras em relação à exigência de como avaliar e à relevância dos itens dos instrumentos ${ }^{(26)}$. Para garantir as explicações claras para proceder a validação, foi elaborado um guia explicativo, detalhando os aspectos, critérios e referências utilizadas.

A avaliação da confiabilidade inter-avaliador é necessária em estudos cujos dados são coletados, por meio de classificações fornecidas por profissionais treinados e não treinados, quantificando o grau de concordância entre os avaliadores ${ }^{(23,27)}$. A concordância inter-avaliador quantifica a proximidade de escores atribuídos por um grupo de avaliadores, quanto mais próxima a pontuação, maior a confiabilidade de coleta de dados ${ }^{(23)}$ e um bom nível de concordância é importante, pois determina a confiança nos itens avaliados ${ }^{(28)}$.

Optou-se em determinar a concordância inter-avaliador neste estudo por meio da estatística $A C 1$ de Gwet, pois são fortes as evidências que mostram que este teste é superior para análise de confiabilidade inter-avaliadores quando comparado a outro teste estatístico ${ }^{(28)}$. AC1 tem melhores propriedades estatísticas pela sua suposta capacidade de corrigir o acordo de porcentagens determinadas por avaliações ao acaso, desenvolvida para que a propensão de avaliação ao acaso seja proporcional à parcela das classificações que podem levar a uma avaliação por não acaso ${ }^{(23)}$.

$\mathrm{Na}$ avaliação da concordância inter-avaliador, foi evidenciando AC1 de Gwet na maioria dos itens (organização e objetividade), classificados conforme Landis e Kock ${ }^{(24)}$ em "quase perfeita" concordância inter-avaliadores e com diferença estatisticamente significante $(p<0,0001)$.

É essencial que a avaliação aconteça de maneira contemporânea, atrativa, relevante e 
conveniente, promovendo mudanças no comportamento por meio de evidências científicas atualizadas. Neste questionário, foram incorporadas as evidências publicadas pela AHA em 2015. A publicação da última atualização da AHA sobre SBV aconteceu em janeiro de 2018, e trouxe informações relevantes em relação ao nível de evidência das ações em RCP no SBV, porém, não foi realizada nenhuma mudança em orientações técnicas e/ ou condutas operacionais ${ }^{(29-30)}$, o que garante que o conteúdo produzido neste estudo é embasado em evidências científicas atualizadas e de repertório internacional.

No processo de construção e validação do questionário, evidenciou-se limitação importante em relação às publicações de estudos sobre elaboração e validação da QME. Além disso, não foi possível realizar a revalidação (realização de teste-reteste) pelos experts após as alterações realizadas mediante as sugestões acatadas, e, ao finalizar o estudo, foi identificada a ausência de abordagem sobre a prevenção de lesões iatrogênicas causadas durante a RCP.

\section{CONCLUSÃO}

O questionário produzido neste estudo apresenta-se válido e pode ser considerado um importante instrumento para o processo de avaliação em estudantes e profissionais da área de saúde, sobre o ensino de RCP no adulto em SBBV com o uso do DEA, no ambiente hospitalar, por elaboração com rigor metodológico.

Na validação, alcançou-se concordância inter-avaliadores satisfatória ("quase perfeita" concordância na maioria dos itens), o que garante que o instrumento é adequado para aplicação no processo de avaliação sobre a temática investigada. Assim, o instrumento poderá conduzir com segurança estratégias de avaliação em atividades de ensino, pesquisa e extensão de maneira contemporânea, confiável e atualizada.

\section{REFERÊNCIAS}

1. Abdulghani HM, Ahmad F, Irshad M, Khalil MS, Al-Shaikh GK, Syed S, et al. Faculty development programs improve the quality of Multiple Choice Questions items' writing. Sci Rep. [Internet]. 2015 [acesso em 07 jan 2018]; 5:9556. Disponível em: http://dx.doi.org/10.1038/srep09556.

2. Vegada B, Shukla A, Khilnani A, Charan J, Desai C. Comparison between three option, four option and five option multiple choice question tests for quality parameters: a randomized study. Indian J Pharmacol. [Internet]. 2016 [acesso em 12 jan 2018]; 48(5):571-5. Disponível em: https://doi.org/10.4103/02537613.190757.

3. Cadorin L, Bagnasco A, Tolotti A, Pagnucci N, Sasso L. Developing an instrument to measure emotional behaviour abilities of meaningful learning through the Delphi technique. J Adv Nurs. [Internet]. 2017 [acesso em 17 jan 2018]; 73(9):2208-18. Disponível em: https://doi.org/10.1111/jan.13273.

4. Oliveira F de, Kuznier TP, Souza CC de, Chianca TCM. Theoretical and methodological aspects for the cultural adaptation and validation of instruments in nursing. Texto contexto- enferm.

[Internet]. 2018 [acesso em 18 ago 2018]; 27(2):1-16. Disponível em: http://dx.doi.org/10.1590/0104070720180004900016.

5. Pugh D, Halman S, Desjardins I, Humphrey-Murto S, Wood TJ. Done or Almost Done? Improving OSCE Checklists to Better Capture Performance in Progress Tests. Teach Learn Med. [Internet]. 2016 [acesso em 02 fev 2018]; 28(4):406-14. Disponível em: https://doi.org/10.1080/10401334.2016.1218337.

6. Wagener S, Möltner A, Tımbıl S, Gornostayeva M, Schultz JH, Brüstle P, et al. Development of a competency-based formative progress test with student-generated MCQs: Results from a multi-centre pilot study. GMS J Med Educ [Internet]. 2015 [acesso em 07 jan 2018]; 32(4). Disponível em: https://doi. 
7. Mafinejad MK, Arabshahi SKS, Monajemi A, Jalili M, Soltani A, Rasouli J. Use of Multi-Response Format Test in the Assessment of Medical Students' Critical Thinking Ability. J Clin Diagn Res. [Internet]. 2017 [acesso em 07 jan 2018]; 11(9):LC10-3. Disponível em: https://doi.org/10.7860/JCDR/2017/24884.10607.

8. Bustraan J, Henny W, Kortbeek JB, Brasel KJ, Hofmann M, Schipper IB. MCQ tests in Advanced Trauma Life Support (ATLSO). Injury. [Internet]. 2016 [acesso em 10 fev 2018]; 47(3):665-8. Disponível em: https:// doi.org/10.1016/j.injury.2015.11.024.

9. Botelho MG, Lam O, Watt RM, Leung D, Kember D. Evaluation of peer-generated MCQs to assess and support learning in a problem-based learning programme. Eur J Dent Educ. [Internet]. 2017 [acesso em 10 jan 2018]. Disponível em: https://doi.org/10.1111/eje.12304.

10. Singh D, Tripathi PK, Patwardhan K. "What do Ayurveda Postgraduate Entrance Examinations actually assess?" - Results of a five-year period question-paper analysis based on Bloom's taxonomy. J Ayurveda Integr Med. [Internet]. 2016 [acesso em 08 jan 2018]; 7(3):167-72. Disponível em: https://doi. org/10.1016/j.jaim.2016.06.005.

11. Surry LT, Torre D, Durning SJ. Exploring examinee behaviours as validity evidence for multiple-choice question examinations. Med Educ. [Internet]. 2017 [acesso em 11 jan 2018]; 51(10):1075-85. Disponível em: https://doi.org/10.1111/medu.13367.

12. Coughlin PA, Featherstone CR. How to Write a High Quality Multiple Choice Question (MCQ): A Guide for Clinicians. Eur J Vasc Endovasc Surg. [Internet]. 2017 [acesso em 02 fev 2018]; 54(5):654-8. Disponível em: https://doi.org/10.1016/j.ejvs.2017.07.012.

13. Goodwin T, Delasobera BE, Strehlow M, Camacho J, Koskovich M, D'Souza P, et al. Indian and United States Paramedic Students: Comparison of Examination Performance for the American Heart Association Advanced Cardiovascular Life Support (ACLS) Training. J Emerg Med. [Internet]. 2012 [acesso em 22 jan 2018]; 43(2):298-302. Disponível em: https://doi.org/10.1016/j.jemermed.2011.05.096.

14. Kleinman ME, Brennan EE, Goldberger ZD, Swor RA, Terry M, Bobrow BJ, et al. Part 5: Adult basic life support and cardiopulmonary resuscitation quality: 2015 American Heart Association Guidelines Update for Cardiopulmonary Resuscitation and Emergency Cardiovascular Care. Circulation. [Internet]. 2015 [acesso em 17 jan 2018]; 132(18 Suppl 2):S414-35. Disponível em: https://doi.org/10.1161/ CIR.0000000000000259.

15. Park IS, Suh YO, Park HS, Kang SY, Kim KS, Kim GH, et al. Item development process and analysis of 50 case-based items for implementation on the Korean Nursing Licensing Examination. J Educ Eval Health Prof. [Internet]. 2017 [acesso em 15 jan 2018]; 14:20. Disponível em: https://doi.org/10.3352/ jeehp.2017.14.20.

16. Rahma NAA, Shamad MMA, Idris MEA, Elfaki OA, Elfakey WEM, Salih KMA. Comparison in the quality of distractors in three and four options type of multiple choice questions. Adv Med Educ Pract. [Internet]. 2017 [acesso em 15 jan 2018]; 8:287-91. Disponível em: https://dx.doi.org/10.2147\%2FAMEP. S128318.

17. Rush BR, Rankin DC, White BJ. The impact of item-writing flaws and item complexity on examination item difficulty and discrimination value. BMC Med Educ. [Internet]. 2016 [acesso em 17 jan 2018]; 16:250. Disponível em: https://doi.org/10.1186/s12909-016-0773-3.

18. Polit DF, Beck CT. Fundamentos de pesquisa em enfermagem: avaliação de evidências para a prática de enfermagem. 7. ed. Porto Alegre: Artmed; 2011.

19. American Heart Association. Destaques da AHA 2015: atualização das diretrizes de RCP e ACE. American Heart Association: Texas (EUA); 2015. [acesso em 03 dez 2017]. 36 p. Disponível em: https:// eccguidelines. heart.org/wp-content/uploads/2015/10/2015-AHA-Guidelines-Highlights-Portuguese.pdf.

20. Case SM, Swanson DB. Constructing written test questions for the basic and clinical sciences. 3. ed. Philadelphia: National Board of Medical Examiners - National Board of Medical Examiners; 2002. 
21. Fehring JR. Methods to validate nursing diagnoses. Heart Lung. [Internet]. 1987 [acesso em 02 jan 2018]; 16(6 Pt 1):625-9. Disponível em: https://www.ncbi.nlm.nih.gov/pubmed/3679856.

22. Bellan MC, Araújo IIM, Araújo S. Capacitação teórica do enfermeiro para o atendimento da Parada Cardiorrespiratória. Rev Bras Enferm. [Internet] 2010 [acesso em 20 fev 2018]; 63(6):1019-27. Disponível em: http://dx.doi.org/10.1590/S0034-71672010000600023.

23. Gwet KL. Computing inter-rater reliability and its variance in the presence of high agreement. $\mathrm{Br} \mathrm{J}$ Math Stat Psychol. [Internet]. 2008 [acesso em 22 jan 2018]; 61(Pt 1):29-48. Disponível em: https://doi. org/10.1348/000711006X126600.

24. Landis JR, Koch GG. The measurement of observer agreement for categorical data. Biometrics. [Internet] 1977 [acesso em 27 dez 2018]; 33(1):159-74. Disponível em: https://www.ncbi.nlm.nih.gov/ pubmed/843571.

25. Alconero-Camarero AR, Gualdrón-Romero A, Sarabia-Cobo CM, Martinez-Arce A. Clinical simulation as a learning tool in undergraduate nursing: validation of a questionnaire. Nurse Educ Today. [Internet]. 2016 [acesso em 27 dez 2017]; 39:128-34. Disponível em: https://doi.org/10.1016/j.nedt.2016.01.027.

26. Faudeux C, Tran A, Dupont A, Desmontils J, Montaudié I, Bréaud J, et al. Development of Reliable and Validated Tools to Evaluate Technical Resuscitation Skills in a Pediatric Simulation Setting: Resuscitation and Emergency Simulation Checklist for Assessment in Pediatrics. J Pediatr. [Internet]. 2017 [acesso em 07 jan 2018]; 188:252-257.e6. Disponível em: https://doi.org/10.1016/j.jpeds.2017.03.055.

27. Hallgren KA. Computing Inter-Rater Reliability for Observational Data: An Overview and Tutorial. Tutor Quant Methods Psychol. [Internet]. 2012 [acesso em 22 jan 2018]; 8(1):23-34. Disponível em: https:// www.ncbi.nlm.nih.gov/pubmed/22833776.

28. Wongpakaran N, Wongpakaran T, Wedding F, Gwet KL. A comparison of Cohen's Kappa and Gwet's AC1 when calculating inter-rater reliability coefficients: a study conducted with personality disorder samples. BMC Med Res Methodol [Internet]. 2013 [acesso em 07 jan 2018]; 13:61. Disponível em: https:// doi.org/10.1186/1471-2288-13-61.

29. Kleinman ME, Goldberger ZD, Rea T, Swor RA, Bobrow BJ, Brennan EE, et al. 2017 American Heart Association Focused Update on Adult Basic Life Support and Cardiopulmonary Resuscitation Quality: An Update to the American Heart Association Guidelines for Cardiopulmonary Resuscitation and Emergency Cardiovascular Care. Circulation. [Internet]. 2018 [acesso em 22 jan 2018]; 137(1):e7-13. Disponível em: https://doi.org/10.1161/CIR.0000000000000539.

30. Perkins GD, Olasveengen TM, Maconochie I, Soar J, Wyllie J, Greif R, et al. European Resuscitation Council Guidelines for Resuscitation: 2017 update. Resuscitation. [Internet]. 2018 [acesso em 23 jan 2018]; 123:43-50. Disponível em: https://doi.org/10.1016/j.resuscitation.2017.12.007.

\section{ANEXO A}

\section{QUESTÕES DE MÚLTIPLA ESCOLHA}

Ressuscitação Cardiopulmonar no adulto em Suporte Básico De Vida com o uso do Desfibrilador Externo Automático no ambiente hospitalar

A seguir estão dispostas 20 questões com quatro alternativas cada ( $A-B-C-D)$ e apenas uma responde corretamente à questão.

Para respondê-las considere o contexto de "Parada Cardiorrespiratória e Ressuscitação Cardiopulmonar no adulto em Suporte Básico de Vida com o uso do Desfibrilador Externo Automático no ambiente hospitalar" e as diretrizes publicadas em 2015 pela American Heart Association.

QUESTÕES: 
1. As condutas relacionadas à etapa de "Vigilância e Prevenção" que compõe a Cadeia da Sobrevivência, para atendimento da Parada Cardiorrespiratória (PCR) no ambiente hospitalar são:

A. Identificação da Parada Cardiorrespiratória; Definição de intervenções efetivas; Detalhamento da queixa.

B. Identificação da Parada Cardiorrespiratória; Implementação de avaliação clínica detalhada;

Definição de intervenções efetivas.

C. Implementação de avaliação clínica com detalhamento da queixa e Definição de intervenções efetivas.

D. Implementação de avaliação clínica detalhada e da Ressuscitação Cardiopulmonar; Definição de intervenções efetiva.

2. Na etapa de "Reconhecimento precoce e pedido de ajuda" deve ser solicitada ajuda imediatamente após identificada a irresponsividade da vítima. Esta etapa consiste em providenciar:

A. Suporte Médico, Carrinho de emergência com desfibrilador e sistema de ventilação.

B. $\quad$ Suporte Médico e sistema de ventilação.

C. Carrinho de emergência com desfibrilador e sistema de ventilação.

D. Suporte Médico, Carrinho de emergência com desfibrilador.

3. A sequência de ações que leva o profissional a reconhecer irresponsividade em uma vítima suspeita de Parada Cardiorrespiratória (PCR) é:

A. Toque superficial ao nível dos ombros da vítima com estímulo auditivo intenso, se possível, chamando a vítima pelo nome.

B. Toque superficial ao nível dos ombros e estímulo auditivo, se possível, chamando a vítima pelo nome.

C. Toque intenso ao nível dos ombros da vítima com estímulo auditivo, obrigatoriamente, chamando a vítima pelo nome.

D. Toque intenso ao nível dos ombros da vítima com estímulo auditivo também intenso, se possível, chamando a vítima pelo nome.

4. Na avaliação do pulso e respiração no reconhecimento da Parada Cardiorrespiratória (PCR) o profissional deve:

A. Verificar pulso carotídeo e, na sequência, respiração, em menos de dez segundos.

B. Verificar pulso carotídeo e, simultaneamente, respiração em menos de dez segundos.

C. Verificar pulso carotídeo e respiração simultaneamente em menos de cinco segundos.

D. Verificar pulso carotídeo e, na sequência, respiração, em menos de cinco segundos.

5. Considerando as ações imediatas mediante o reconhecimento da Parada Cardiorrespiratória (PCR), análise o cenário: " $X$ e Y são enfermeiros e estão na Sala de Emergência de um hospital, onde é admitido um paciente em Parada Cardiorrespiratória (PCR)". A conduta recomendada a ser realizada de maneira simultânea por $X$ e $Y$ é:
A. $\quad Y$ inicia as Compressões Torácica Externa e $X$ implementa a etapa de "Pedido de ajuda".
B. $\quad Y$ inicia as Compressões Torácica Externa e $X$ permeabiliza as Vias Aéreas.
C. Y implementa a etapa de "Pedido de Ajuda" e $X$ permeabiliza as Vias Aéreas.
D. Y implementa a etapa de "Pedido de Ajuda" e X realiza ventilação com Bolsa-valva-máscara.

6. A troca de profissional durante a realização da Compressão Torácica Externa (CTE) é ser a cada:
A. 90 segundos.
B. 120 segundos.
C. 180 segundos.
D. 60 segundos.

7. O local indicado, no tórax da vítima, para posicionamento das mãos do profissional na execução da Compressão Torácica Externa (CTE) é:
A. Terço médio do esterno.
B. Metade superior do esterno.
C. Terço inferior do esterno.
D. Metade inferior do esterno

8. A profundidade indicada nas Compressões Torácica Externa (CTE) de uma vítima adulta é:

A. $\quad$ Pelo menos $4 \mathrm{~cm}$, mas não deve ser superior a $5 \mathrm{~cm}$.

B. Pelo menos $6 \mathrm{~cm}$, mas não deve ser superior a $8 \mathrm{~cm}$. 
C. Pelo menos $5 \mathrm{~cm}$, mas não deve ser superior a $6 \mathrm{~cm}$.

D. Pelo menos $4 \mathrm{~cm}$, mas não deve ser superior a $6 \mathrm{~cm}$.

9. A frequência, por minuto, indicada nas Compressões Torácica Externa (CTE) é:

A. $\quad 100$ a 120 por minuto.

B. $\quad 60$ a 90 por minuto.

C. Superior a 120 e inferior a 140.

D. Superior a 60 e inferior a 100.

10. Em relação ao retorno da parede torácica pela descompressão na Compressão Torácica Externa (CTE), o profissional deve:

A. Garantir leve afastamento do tórax pelas mãos do profissional.

B. Permitir o retorno total do tórax.

C. Manter leve compressão no tórax.

D. Realizar o movimento de "galope" (afastar região hipotênar do tórax da vítima) pelas mãos do profissional.

11. Para a permeabilização das Vias Aéreas (VVAA), na Ressuscitação Cardiopulmonar (RCP), quando não há suspeita de lesão cervical, é indicado:

A. Elevação da cabeça pela flexão do pescoço.

B. Lateralização da cabeça pela hiperextensão do pescoço.

C. Elevação da cabeça pela hiperextensão do pescoço.

D. Lateralização da cabeça pela flexão do pescoço.

12. Para realizar o manejo adequado da bolsa durante a ventilação com Bolsa-valva-máscara deve:

A. Pressionar lentamente todo o centro da bolsa, em cada ventilação.

B. Pressionar rapidamente, em seis segundos, as extremidades da bolsa, em cada ventilação.

C. Pressionar lentamente as extremidades da bolsa, em cada ventilação.

D. Pressionar rapidamente, em um segundo, todo o centro da bolsa, em cada ventilação.

13. Em uma vítima adulta, quando a Compressão Torácica Externa (CTE) é realizada sincronizadas com a ventilação por Bolsa-valva-máscara é recomendado:

A. Realizar ciclos de 30 Compressões Torácica Externa acompanhadas por duas Ventilações de resgate com Bolsa-valva-máscara.

B. Realizar ciclos de 15 Compressões Torácica Externa acompanhadas por uma Ventilação de resgate com Bolsa-valva-máscara.

C. Realizar ciclos de 20 Compressões Torácica Externa acompanhadas por duas Ventilações de resgate por Bolsa-valva-máscara.

D. Realizar ciclos de 50 Compressões Torácica Externa acompanhadas por uma Ventilação de resgate por Bolsa-valva-máscara.

14. Na chegada do Desfibrilador Externo Automático (DEA) no local da Parada Cardiorrespiratória (PCR), a conduta imediata é:

A. Aderir as pás no tórax da vítima.

B. Finalizar o ciclo das Compressões Torácica Externa.

C. Abrir e ligar o equipamento.

D. Interromper as Compressões Torácica Externa para implementar o Desfibrilador Externo

Automático (DEA).

15. Na vítima em Parada Cardiorrespiratória (PCR), os ritmos cardíacos que não são indicados o choque pelo Desfibrilador Externo Automático (DEA) são:

A. Atividade Elétrica sem Pulso e Taquicardia Ventricular sem pulso.

B. Fibrilação Ventricular e Assistolia.

C. Fibrilação Ventricular e Taquicardia Ventricular sem pulso.

D. Assistolia e Atividade Elétrica sem Pulso.

16. Considerando os ritmos cardíacos em que acontece a indicação do choque pelo Desfibrilador Externo Automático (DEA), avalie o cenário: "X e Y estão em atendimento de uma Parada Cardiorrespiratória (PCR) com o uso do Desfibrilação Externa Automática (DEA), o equipamento avalia o ritmo e o choque é recomendado". Os possíveis ritmos cardíacos da vítima são:

A. Assistolia e Atividade Elétrica sem Pulso. 
B. Fibrilação Ventricular e Taquicardia Ventricular sem pulso.

C. Atividade Elétrica sem Pulso e Taquicardia Ventricular sem pulso.

D. Fibrilação Ventricular e Assistolia.

17. A conduta recomendada ao profissional em um cenário que o Desfibrilador Externo Automático (DEA) avalia o ritmo cardíaco e não indica o choque é:

A. Reiniciar a Ressuscitação Cardiopulmonar.

B. Interromper a Ressuscitação Cardiopulmonar.

C. Avaliação do pulso e respiração da vítima.

D. Reavaliar o ritmo cardíaco.

18. Com o retorno da circulação espontânea após uso do Desfibrilador Externo Automático (DEA), é recomendado:

A. Desligar o equipamento e retirar as pás do tórax da vítima.

B. Não desligar o equipamento e retirar as pás do tórax da vítima.

C. Desligar o equipamento e manter as pás aderidas ao tórax da vítima.

D. Não desligar o equipamento e manter as pás aderidas ao tórax da vítima.

19. Compõe a quinta e última etapa na Cadeia da Sobrevivência ("Suporte Avançado de Vida - SAV e cuidados pós Parada Cardiorrespiratória - PCR"), para atendimento da Parada Cardiorrespiratória (PCR) no ambiente intra-hospitalar:

A. Investigação para identificação e tratamento da causa da Parada Cardiorrespiratória.

B. Aplicação da desfibrilação.

C. Assistência exclusiva pelo profissional médico.

D. Assistência exclusiva pelo profissional enfermeiro.

20. Em relação da divisão dos itens para registro das informações no instrumento In-hospital Utstein Style é correto afirmar:

A. Dividido em três blocos de informações, relacionado ao paciente, ao momento da Parada Cardiorrespiratória e resultados da Ressuscitação Cardiopulmonar.

B. Dividido em dois blocos de informações, relacionado ao paciente e ao momento/resultados da Ressuscitação Cardiopulmonar.

C. Um único bloco de itens para registro dos resultados da Ressuscitação Cardiopulmonar.

D. Dividido em dois blocos de informações, relacionado ao momento da Parada Cardiorrespiratória e resultados da Ressuscitação Cardiopulmonar.

\section{ANEXO B}

\section{RESPOSTAS DAS QUESTÕES DE MÚLTIPLA ESCOLHA}

\section{QUESTÃO ENUNCIADO ALTERNATIVA CORRETA}

$1 \quad$ As condutas relacionadas à etapa de "Vigilância e Prevenção" que compõe a Cadeia da Sobrevivência, para atendimento da Parada Cardiorrespiratória no ambiente hospitalar são: C $2 \quad \mathrm{Na}$ etapa de "Reconhecimento precoce e pedido de ajuda" deve ser solicitada ajuda imediatamente após identificada a irresponsividade da vítima. Esta etapa consiste em providenciar: 3 A sequência de ações que leva o profissional a reconhecer irresponsividade em uma vítima suspeita de Parada Cardiorrespiratória é:

$4 \quad \mathrm{Na}$ avaliação do pulso e respiração no reconhecimento da Parada Cardiorrespiratória o profissional deve: $B$

5 Considerando as ações imediatas mediante o reconhecimento da Parada Cardiorrespiratória (PCR), analise o cenário: "X e Y são enfermeiros e estão na Sala de Emergência em um hospital, onde é admitido um paciente em Parada Cardiorrespiratória (PCR)". A conduta recomendada a ser realizada de maneira simultânea por $\infty$ e $\mu$ é: $\quad$ A

6 A troca do profissional durante a realização da Compressão Torácica Externa (CTE) é a cada: $B$

7 O local indicado, no tórax da vítima, para posicionamento das mãos do profissional na execução da Compressão Torácica Externa é:

8 A profundidade indicada nas Compressões Torácica Externa de uma vítima adulta é: 
A frequência, por minuto, indicada nas Compressões Torácica Externa é: A

10 Em relação ao retorno da parede torácica pela descompressão na Compressão Torácica Externa, o profissional deve:

11 Para a permeabilização das Vias Aéreas, na Ressuscitação Cardiopulmonar, quando não há suspeita de lesão cervical, é indicado:

C

12 Para realizar o manejo adequado da bolsa durante a ventilação com Bolsa-valva-máscara é:

13 Em uma vítima adulta, quando a Compressão Torácica Externa é realizada simultaneamente com a ventilação por Bolsa-valva-máscara é recomendado:

A

14 Na chegada do Desfibrilador Externo Automático (DEA), no local da Parada Cardiorrespiratória, a conduta imediata é: C

15 Na vítima em Parada Cardiorrespiratória (PCR), os ritmos cardíacos que não são indicados o choque pelo Desfibrilador Externo Automático (DEA) são: D

16 Considerando os ritmos cardíacos em que acontece a indicação do choque pelo Desfibrilador Externo Automático (DEA), avalie o cenário: "X e Y estão em atendimento de uma Parada

Cardiorrespiratória (PCR) com o uso do Desfibrilação Externa Automática (DEA), o equipamento avalia o ritmo e o choque é recomendado". Os possíveis ritmos cardíacos da vítima são: $B$

17 A conduta recomendada ao profissional em um cenário que o Desfibrilador Externo Automático (DEA) avalia o ritmo cardíaco e não indica o choque é: C

18 Com o retorno da circulação espontânea após uso do Desfibrilador Externo Automático (DEA), é recomendado:

19 Compõe a quinta e última etapa na Cadeia da Sobrevivência ("Suporte Avançado de Vida - SAV e cuidados pós Parada Cardiorrespiratória - PCR"), para atendimento da Parada Cardiorrespiratória no ambiente intra-hospitalar: A

20 Em relação da divisão dos itens para registro das informações no instrumento Utstein Style é correto afirmar:

B

Recebido: 29/01/2019

Finalizado: 20/08/2019

Autor Correspondente:

Mateus Goulart Alves

Faculdade Atenas

R. Amarantos, 1000 - 37900-380 - Passos, MG, Brasil

E-mail: mateusgoulartalves@gmail.com

Contribuição dos autores:

Contribuições substanciais para a concepção ou desenho do estudo; ou a aquisição, análise ou interpretação de dados do estudo - MGA, VSP, DFGB, ALPCC, MCBD

Elaboração e revisão crítica do conteúdo intelectual do estudo - MGA, VSP, DFGB, ALPCC, JSGN, MCBD

Aprovação da versão final do estudo a ser publicado - MGA, VSP, DFGB, ALPCC, JSGN, MCBD

Responsável por todos os aspectos do estudo, assegurando as questões de precisão ou integridade de qualquer parte do estudo - MGA, MCBD 